01,13

\title{
Межфазная энергия на границе металлический кристалл-расплав
}

\author{
() Л.П. Аресьева ${ }^{1}$, И.Г. Шебзухова ${ }^{2}$ \\ Донской государственный технический университет, \\ Ростов-на-Дону, Россия \\ ${ }^{2}$ Кабардино-Балкарский государственный университет, \\ Нальчик, Россия \\ E-mail: Ludmilochka529@mail.ru, Irina.Shebzukhova@mail.ru \\ (Поступила в Редакцию 10 января 2018 г. \\ В окончательной редакции 12 февраля 2018 г.)
}

\begin{abstract}
Разработана методика оценки межфазной энергии нанокристаллов переходных металлов и ее анизотропии на границе с собственным расплавом. Получено выражение для координаты границы Гиббса с учетом размерной зависимости. Межфазная энергия кристаллических граней на границе с собственным расплавом мономорфных $4 d$ - и $5 d$-металлов нелинейно уменьшается при уменьшении размера нанокристалла и при определенном размере исчезает. При радиусе нанокристалла более $10 \mathrm{~nm}$ межфазная энергия граней приближается к значениям для макрокристалла. Температурная зависимость межфазной энергии на фазовой границе кристалл-расплав практически линейна. Показано, что разработанная методика находится в согласии с известными экспериментальными данными для моно- и поликристаллов и пригодна для оценки ориентационной, температурной и размерной зависимостей межфазной энергии нано-, микро- и макрокристаллов на границе с собственным расплавом.
\end{abstract}

DOI: $10.21883 /$ FTT.2018.07.46108.010

\section{1. Введение}

Уменьшение свободной энергии, в том числе межфазной энергии (МЭ), системы является движущей силой фазовых переходов, включая процессы кристаллизации и плавления. Межфазная энергия определяется как обратимая работа, необходимая для создания единицы площади межфазной границы между кристаллом и контактирующей с ним жидкой фазой и является фундаментальной характеристикой материалов.

Существует ряд экспериментальных методов, позволяющих измерить МЭ или межфазное натяжение $(\mathrm{MH})$ кристалла на границе с собственным расплавом - в опытах по переохлаждению расплава [1-3], по двугранному углу [4-6] и форме малоугловой границы зерен $[7,8]$, по понижению температуры плавления частиц малых размеров [9], молекулярной динамики [10-13]. Данные, полученные указанными методами, имеют заметный разброс.

Как известно, большинство свойств и параметров кристаллов изменяются при уменышении размеров. Измерение МЭ с технической точки зрения процедура весьма непростая и трудоемкая. Поэтому до сих пор для переходных металлов данные по МЭ либо вообще отсутствуют, либо сильно расходятся. Однако для моделирования процессов зарождения и роста новой фазы и управления ими знание данной зависимости необходимо.

Также на протяжении нескольких десятилетий развивались теоретические методы оценки МЭ или МН макрокристаллов и малых частиц, которые условно можно разделить на следующие группы: термодинамические [14-19], структурно-термодинамические [20,21], молекулярно-статистические [3] и электронно-статисти- ческие [22-28]. Термодинамические методы позволяют выразить МЭ металлических моно- и поликристаллов через температуры и теплоты фазовых превращений [14-18], а также позволяют учесть вклад автоадсорбции в величину МЭ поликристалла [19]. В работах Магомедова $[17,18]$ проведен последовательный анализ зависимостей скрытой теплоты, скачков объема и МЭ при фазовом переходе кристалл-жидкость от размера и формы кристаллов. Показано, что для любого однокомпонентного вещества МЭ кристалла должна исчезать при определенном размере наночастицы. При данном размере скрытая теплота фазового перехода кристалл-жидкость становится равной нулю и исчезает различие фаз. Форма нанокристаллов в общем случае может быть произвольной, но наиболее равновесной из возможных изоморфных форм (пластинчатой, стержневидной и кубической) является кубическая [17].

В работах $[22,23]$ для расчета ориентационной зависимости МЭ простых металлов на границе с собственным расплавом был развит электронно-статистический метод, который в дальнейшем распространили на случай переходных металлов с учетом зависимости МЭ от температуры [24,25] и размеров кристалла [26].

В обзоре [28] проанализированы экспериментальные данные о форме металлических частиц с размерами менее $100 \mathrm{~nm}$. Малые металлические частицы могут иметь форму сферы или многогранника. Возможно также сосуществование граней и скругленных участков поверхности. При росте температуры происходит уменьшение площади граней, т.е. термическое загрубление поверхности.

В настоящей работе ставилась цель в рамках электронно-статистического метода описать размерную зави- 
симость МЭ граней кристаллов мономорфных $4 d$ - и $5 d$-металлов на границе с собственным расплавом.

\section{2. Координата границы Гиббса и электронная плотность металлического нанокристалла}

Рассмотрим металлический кристалл малого размера, покрытый слоем расплава. Будем считать, что контактирующие фазы находятся в термодинамическом равновесии. Поведение коллективизированных электронов переходных металлов вблизи межфазной границы с расплавом описывается с помощью изотропной модели металла. Физическую $R$ и гиббсову $R_{\Gamma}$ поверхности раздела кристалл-расплав выбираем также, как в работах [22-28].

Электронная плотность и потенциал вблизи границы раздела металлический нанокристалл-расплав находим из уравнения Томаса-Ферми аналогично работам $[22,24,26]$. Уравнения Томаса-Ферми для малого металлического кристалла, окруженного слоем собственного расплава макроскопической толщины, выраженные через безразмерные координату $\varepsilon=r / s$ и потенциал $\chi(\varepsilon)=V(r) / V_{R}$ записываются в виде

$$
\begin{array}{r}
\varepsilon \chi^{\prime \prime}(\varepsilon)+2 \chi^{\prime}(\varepsilon)=\varepsilon\left|\chi^{3 / 3}(\varepsilon)-1\right| \text { при } 0 \leq \varepsilon \leq \varepsilon_{R}, \\
\varepsilon \chi^{\prime \prime}(\varepsilon)+2 \chi^{\prime}(\varepsilon)=\varepsilon\left[\chi^{3 / 2}(\varepsilon)-\frac{1}{1+p}\right] \\
\text { при } \quad \varepsilon_{R} \leq \varepsilon \leq+\infty .
\end{array}
$$

Здесь $s-$ коэффициент, выражающийся через потенциал Ферми металла (параметр, приводящий уравнение Томаса-Ферми к безразмерному виду), $p$ относительное изменение плотности металла при фазовом переходе, $V_{R}=(5 / 3)\left(k_{k} / e\right) \rho^{2 / 3}(0)-$ потенциал Ферми в центре кристалла, $e=4.8 \cdot 10^{-10}$ СГСЭ, $k_{k}=(3 / \pi)^{2 / 3}\left(3 h^{2} / 40 m\right), m-$ масса электрона, $h-$ постоянная Планка.

Граничные условия для уравнений (1) и $(2): \chi(\varepsilon)=1$ и $\chi^{\prime}(\varepsilon)=0$ при $\varepsilon=0, \chi(\varepsilon)=(1-p)^{2 / 3}$ и $\chi^{\prime}(\varepsilon)=0$ при $\varepsilon=+\infty$, а на физической поверхности раздела нанокристалл-расплав $\left(\varepsilon=\varepsilon_{R}\right)$ функции $\chi(\varepsilon)$ и $\chi^{\prime}(\varepsilon)$ являются непрерывными.

Выражения для электронной плотности и потенциала с учетом внутренней области нанокристалла и внешней среды можно записать

$$
\begin{gathered}
\rho(r)=\rho(0)\left\lfloor\chi_{i}^{3 / 2}(\varepsilon) \cdot \theta\left(\varepsilon_{R}-\varepsilon\right)+\chi_{e}^{3 / 2}(\varepsilon) \cdot \theta\left(\varepsilon_{R}+\varepsilon\right)\right\rfloor, \\
V(r)=V_{R}\left\lfloor\chi_{i}(\varepsilon) \cdot \theta\left(\varepsilon_{R}-\varepsilon\right)+\chi_{e}(\varepsilon) \cdot \theta\left(\varepsilon_{R}+\varepsilon\right)\right\rfloor,
\end{gathered}
$$

где $\theta\left(\varepsilon_{R} \pm \varepsilon\right)$ - ступенчатая функция Хэвисайда, $\rho(0)-$ электронная плотность металла в центре нанокристалла.

Электронную плотность и потенциал нанокристалла можно выразить через электронную плотность $\rho(\infty)=z / \Omega$ и потенциал $V_{i}$ полубесконечного кристалла

$$
\begin{gathered}
\rho(r)=\rho(0) \chi^{3 / 2}(\varepsilon)=\lambda \rho(\infty) \chi^{3 / 2}(\varepsilon), \\
V(r)=V_{R} \chi(\varepsilon)=\lambda^{2 / 3} V_{i} \chi(\varepsilon),
\end{gathered}
$$

где $z$ - число свободных электронов на атом, $\Omega$ объем ячейки Вигнера-Зейтца-Свэттера.

Решениями уравнений (1) и (2) для внутренней и внешней частей системы с учетом граничных условий являются функции

$$
\begin{aligned}
& \chi_{i}(\varepsilon)=1-\frac{1-\chi_{p}\left(\varepsilon_{R}\right)}{\left(1-\left(\varepsilon-\varepsilon_{R}\right) / c\right)^{6}} \quad \text { при } 0 \leq \varepsilon \leq \varepsilon_{R}, \\
& \chi_{e}(\varepsilon)=\frac{1}{(1+p)^{2 / 3}}+\frac{A}{\left(1+\left(\varepsilon-\varepsilon_{R}\right) / c\right)^{n}} \\
& \text { при } \varepsilon_{R} \leq \varepsilon \leq+\infty .
\end{aligned}
$$

Здесь $\chi_{p}\left(\varepsilon_{R}\right), c, A$ и $n$ найдены из условий непрерывности $\chi(\varepsilon)$ и $\chi^{\prime}(\varepsilon)$ на межфазной границе и из предельного перехода $(8)$ к функции $\chi_{e}(\varepsilon)$ для случая наночастица-вакуум

$$
\begin{gathered}
\chi_{p}\left(\varepsilon_{R}\right)=\frac{3}{5} \cdot \frac{1+p}{p}\left[1-\frac{1}{(1+p)^{5 / 3}}\right], \quad c=2.1 \cdot(125 / 3)^{1 / 4}, \\
A=\chi_{p}\left(\varepsilon_{R}\right)-(1+p)^{-2 / 3}, \quad n=6 \cdot \frac{1-\chi_{p}\left(\varepsilon_{R}\right)}{A},
\end{gathered}
$$

Значение безразмерного коэффициента $\lambda$ найдено из закона сохранения электронного заряда зерна нанокристалла

$$
\lambda=\frac{p \varepsilon_{R}^{3}(1-\delta)^{3}}{3\left\{\int_{0}^{\varepsilon_{R}}\left[\chi_{i}^{3 / 2}(\varepsilon)-(1+p)^{-1}\right] \varepsilon^{2} d \varepsilon+\int_{\varepsilon_{R}}^{\infty}\left[\chi_{e}^{3 / 2}(\varepsilon)-(1+p)^{-1}\right] \varepsilon^{2} d \varepsilon\right\}},
$$

где $\delta \cong \varepsilon_{R}^{-1}$ - коэффициент разрыхления. При разложении подынтегральных выражений в (11) в степенные ряды можно ограничиться первыми двумя членами ряда, так как модули вторых слагаемых в выражениях (7) и (8) много меньше единицы. После преобразований получим выражение для безразмерного коэффициента $\lambda$, учитывающее зависимость величин от изменения плотности фаз на границе раздела и линейного размера нанокристалла. C увеличением размера нанокристалла значение $\lambda$ возрастает по полиномиальному закону и стремится к единице. Следовательно, при $\varepsilon_{R} \rightarrow \infty$ происходит предельный переход от нанокристалла к макрокристаллу, что позволяет использовать выражения (7) и (8) при описании свойств нано-, микро- и макроразмерных систем.

График электронной плотности металла $\rho(r)$ и ее зависимость от размера кристалла показаны на рис, 1 на примере иридия. Как видно из рис. 1, при уменьшении размера кристалла уровень электронной плотности иридия нелинейно снижается по сравнению с макрокристаллом. Ход электронной плотности становится более пологим. Данные закономерности справедливы для всех рассматриваемых в работе металлов. 


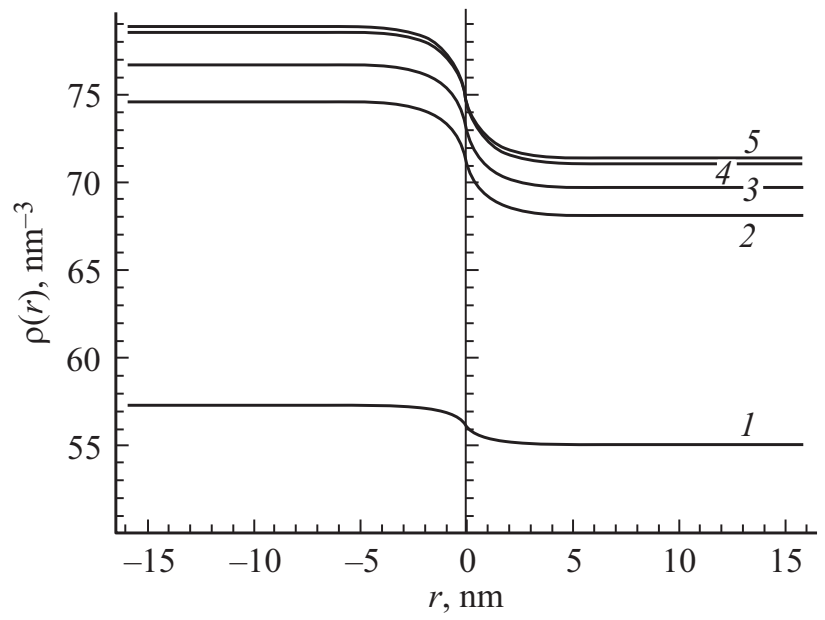

Рис. 1. Зависимость электронной плотности иридия от размера кристалла: $1-2 \mathrm{~nm} ; 2-5 \mathrm{~nm} ; 3-10 \mathrm{~nm} ; 4-100 \mathrm{~nm}$; 5 - макрокристалл.

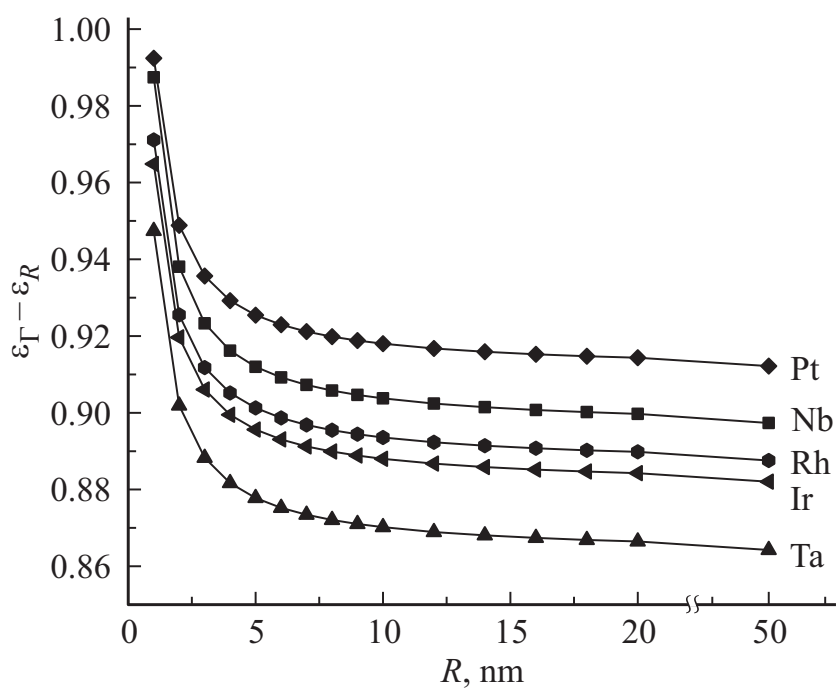

Рис. 2. Зависимость координаты гиббсовой поверхности раздела на границе металлический кристалл-расплав от размера кристалла.

Межфазная энергия грани $f_{\omega 12}^{(T)}(h k l)$ определяется относительно гиббсовой поверхности раздела нанокристалл металла-собственный расплав. Координата гиббсовой поверхности раздела $\varepsilon_{\Gamma}$ для системы нанокристалл металла-расплав находится из условия электронейтральности на границе контакта фаз

$$
\begin{aligned}
\varepsilon_{\Gamma}= & \varepsilon_{R}-\frac{3}{2} \frac{A c(1+p)^{2 / 3}}{p(n-1)} \\
& -\frac{3 c\left(1-\chi_{p}(0)\right)(1+p)}{10 p}\left(1-\left(1+\frac{\varepsilon_{R}}{c}\right)^{-5}\right) .
\end{aligned}
$$

На рис. 2 представлена зависимость координаты гиббсовой поверхности раздела частица-расплав в ви- де $\varepsilon_{\Gamma}-\varepsilon_{R}$ от размера частицы для пяти переходных металлов.

Координата границы Гиббса $\varepsilon_{\Gamma}>\varepsilon_{R}$, что объясняется вытягиванием „хвоста“ электронной плотности во внешнюю область системы. Как видно из графиков (рис. 2), при увеличении размера частицы величина $\varepsilon_{\Gamma}-\varepsilon_{R}$ для всех металлов уменьшается и примерно при $100 \mathrm{~nm}$ становится равной координате границы Гиббса макрокристалла, т.е. гиббсова поверхность раздела при увеличении геометрических размеров кристалла сдвигается в сторону физической поверхности раздела.

\section{3. Межфазная энергия металлического нанокристалла на границе с собственным расплавом}

Используя термодинамическое определение Гиббса для МЭ металла на границе с расплавом, и учитывая температурный вклад, МЭ граней представим в виде

$$
\begin{aligned}
f_{\omega 12}^{(T)}(h k l)= & f_{\omega 12}^{(i 0)}(h k l)+f_{\omega 12}^{(e 0)}(h k l) \\
& +\Delta f_{\omega 12}^{(i T)}(h k l)+\Delta f_{\omega 12}^{(e T)}(h k l) .
\end{aligned}
$$

Здесь $f_{\omega 12}^{(i 0)}$ и $f_{\omega 12}^{(e 0)}(h k l)$ - внутренний и внешний вклады в МЭ граней нанокристалла при $0 \mathrm{~K}, \Delta f_{\omega 12}^{(i T)}(h k l)$ и $\Delta f_{\omega 12}^{(e T)}(h k l)$ - внутренний и внешний температурные вклады в МЭ граней.

При расчете МЭ нанокристаллов $d$-металлов на границе с собственным расплавом учитывались вклады электрон-электронного, электрон-ионного и ион-ионного взаимодействий в энергию решетки кристалла и соответствующие плотности энергий для расплава. Отдельные слагающие энергии элементарного шара, входящие в $f_{\omega 12}^{(i 0)}(h k l)$ и $f_{\omega 12}^{(e 0)}(h k l)$, вычислялись по формулам из работы [30].

На рис. 3 показана размерная зависимость внутреннего вклада в МЭ кристаллов переходных металлов на примере граней (110) и (111) молибдена, вольфрама, иридия и платины. Как видно, с уменьшением размера кристаллов внутренний вклад в МЭ граней убывает нелинейно. При размера кристалла порядка 10-12 nm величина внутреннего вклада приближается к значениям для макрокристалла и ее рост значительно замедляется. Данные закономерности справедливы и для других мономорфных $4 d$ - и $5 d$-металлов.

Межфазная энергия граней кристаллов рассчитывалась для трех температур - 0 K, 293 K, температуре плавления макрокристалла. Температурный вклад в МЭ нанокристаллов и тонких пленок рассматривался нами ранее в работе [26].

Температурный вклад в МЭ внутренней области нанокристалла состоит из слагаемого, обусловленного 

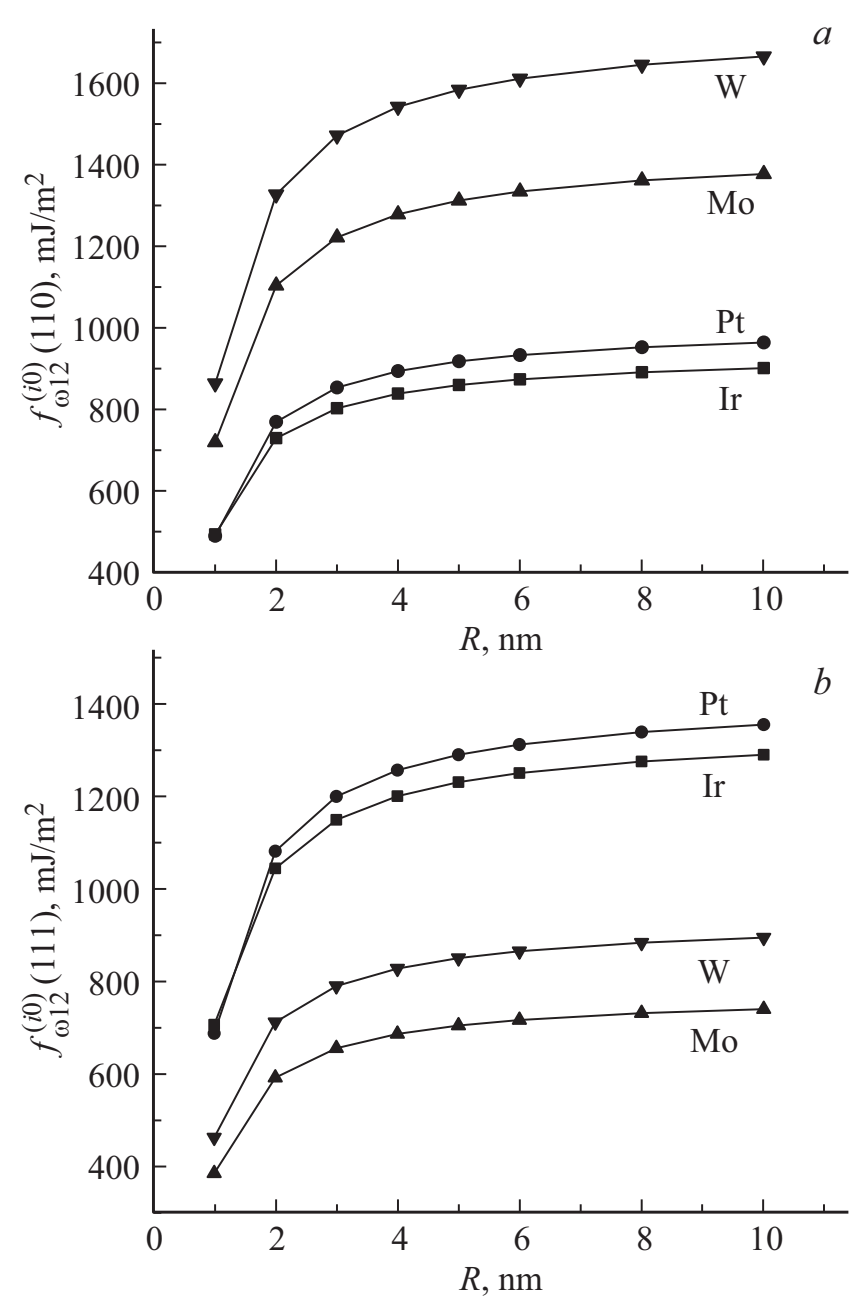

Рис. 3. Размерная зависимость внутреннего вклада в МЭ граней нанокристаллов $d$-металлов на границе с собственным расплавом.

ионной компонентой металла

$$
\begin{aligned}
& \Delta f_{\omega 12}^{(T u)}(h k l)=\left(1-\chi_{p}(0)\right) \\
& \quad \times\left(-\frac{9}{4} k_{B} T n(h k l)-9 s\left(\frac{k_{B} R^{*} \theta \alpha_{l} T}{\hbar}\right)^{2} D^{*}\right) \sum_{k=0} \Psi^{-6},
\end{aligned}
$$

и слагаемого, обусловленного размытием уровня Ферми металла

$$
\begin{aligned}
& \Delta f_{\omega 12}^{(T e)}=-\frac{\pi^{2} k_{B}^{2} c s T^{2}}{4 e V_{R}} \rho(0) \\
& \quad \times\left(\frac{A}{2(1+p)^{1 / 3}(n-1)}-\frac{1-\chi_{p}(0)}{10}-\Phi \frac{p}{1+p}\right) .
\end{aligned}
$$

Здесь $\left.\Psi=\left(1-(\varepsilon)_{k}-\varepsilon_{R}\right) / c\right), \Phi=\left(\varepsilon_{\Gamma}-\varepsilon_{R}\right) / c, k_{B}-$ постоянная Больмана, $\theta-$ температура Дебая, $\alpha_{l}-$ температурный коэффициент линейного расширения, $R^{*}-$ радиус $s$-сферы, $\hbar$ - постоянная Планка, $D^{*}=D(1-\delta)$, $D$ - плотность кристалла.
Формула (14) учитывает ориентационную зависимость температурного вклада в МЭ металлических нанокристаллов.

Температурный вклад в МЭ для внешней области системы получен в виде

$$
\begin{aligned}
\Delta f_{\omega 12}^{(e T)}= & \frac{9}{4} \operatorname{csk}_{B} n_{e v} T \frac{A(1+p)^{-2 / 3}}{(1+\Phi)^{n-1}} \\
& \times\left[\frac{1}{n-1}-\frac{1}{2 n-1} \frac{A(1+p)^{-2 / 3}}{(1+\Phi)^{n}}\right],
\end{aligned}
$$

где $n_{e v}$ - число частиц в единице объема расплава.

Размерная зависимость температурного вклада в МЭ граней рассчитана по формулам (14)-(16). Температурный вклад в МЭ граней отрицателен, по величине составляет десятки $\mathrm{mJ} / \mathrm{m}^{2}$ для разных граней при температурах плавления макрокристаллов. При увеличении размера нанокристалла температурный вклад в МЭ граней по величине возрастает (рис. 4).

Для расчета поляризации поверхностных ионов на межфазной границе металлический нанокристалл-расплав мы преобразовали формулу из [31] для границы металл-вакуум. Деформационную энергию поляризации ионов в $k$-слое грани в расчете на элементарный шар можно определить как

$$
f_{\omega}^{(p)}=-\frac{18 \alpha \lambda^{3} V_{R}^{2}}{\xi^{2} s^{2}} \frac{\left[1-\chi_{p R}(0)\right]^{2}}{c^{2}} n(h k l) \sum_{k} \Psi^{-14}
$$

где $\alpha$ - поляризуемость ионов, $n(h k l)-$ концентрация частиц на грани $(h k l), \xi-$ коэффициент, учитывающий обменное взаимодействие, $k$ - номер атомного слоя.

Деформационная энергия поляризации ионов отрицательна, по абсолютной величине мала $\left(\sim 10^{-4} \mathrm{~mJ} / \mathrm{m}^{2}\right)$ и имеет значительную анизотропию. Размерную зависимость поляризационной поправки можно также как и

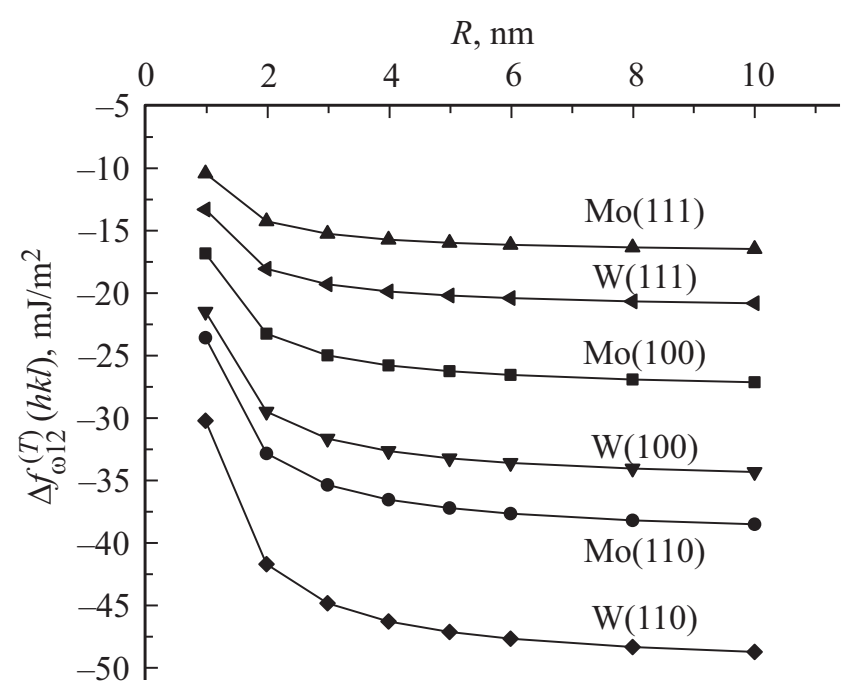

Рис. 4. Размерная зависимость температурного вклада в МЭ граней кристаллов вольфрама и молибдена на границе с собственным расплавом. 


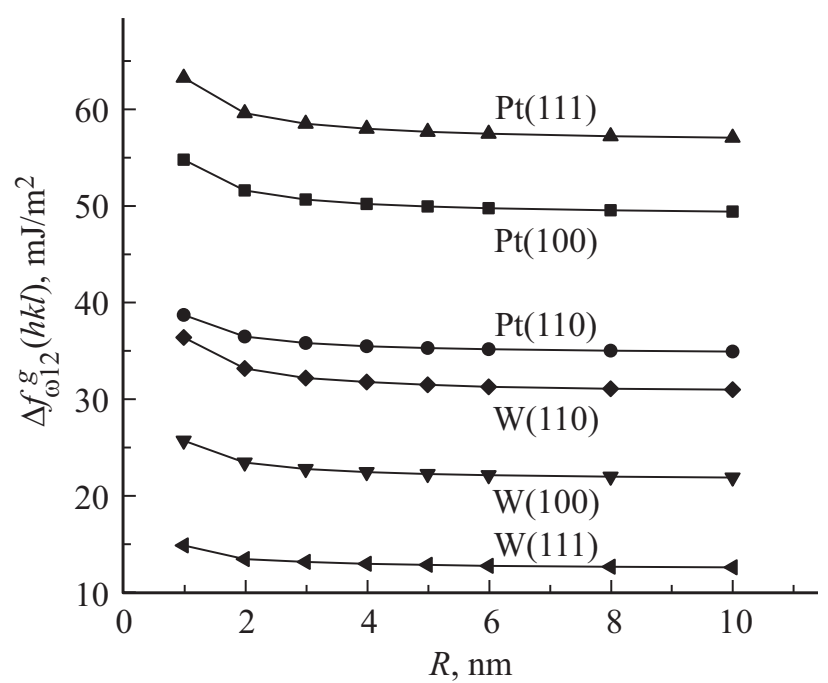

Рис. 5. Размерная зависимость дисперсионного вклада в МЭ граней нанокристалла.

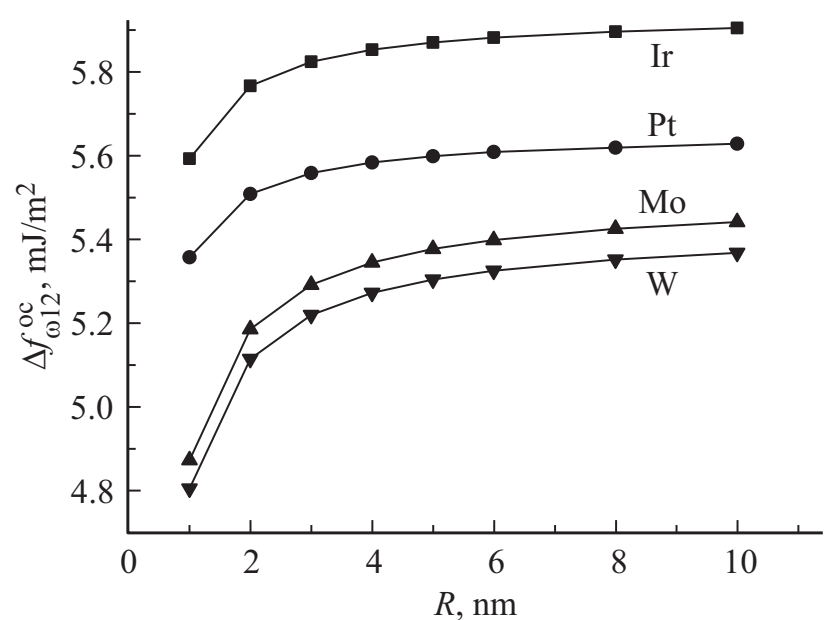

Рис. 6. Размерная зависимость осцилляционного вклада в МЭ нанокристалла.

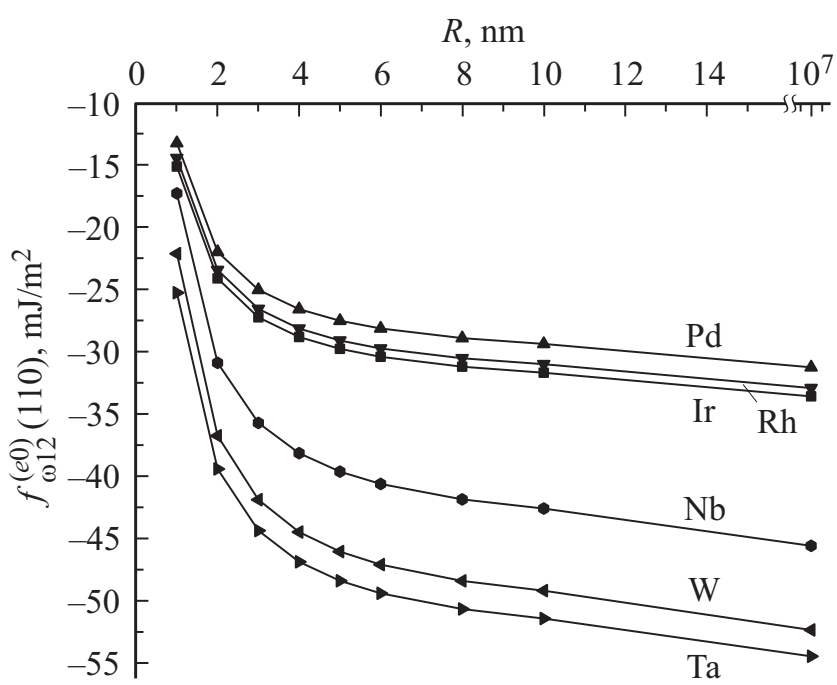

Рис. 7. Размерная зависимость внешнего вклада в МЭ граней нанокристаллов $d$-металлов на границе с собственным расплавом. зависимость внутреннего вклада, выразить полиномом шестого порядка.

Также оценены осцилляционная $f_{\omega 12}^{o c}$ и дисперсионная $f_{\omega 12}^{g}(h k l)$ поправки к внутреннему вкладу МЭ. На рис. 5 и 6 показаны зависимости $f_{\omega 12}^{o c}$ и $f_{\omega 12}^{g}(h k l)$ на границе металлический нанокристалл-собственный расплав от радиуса кристалла. Осцилляционная и дисперсионная поправки к МЭ рассматриваемых металлов положительны, вносят вклад в величину $f_{\omega 12}^{(i 0)}(h k l)$ менее $1 \%$ и от 0.5 до 6\% соответственно. Величина $f_{\omega 12}^{g}(h k l)$ является нелинейной убывающей функцией размера кристалла. Осцилляционная поправка с ростом $R$ незначительно увеличивается.

Нами получено выражение для вклада в МЭ внешней части распределения электронного газа с учетом скачка плотности при фазовом переходе кристалл-расплав и линейных размеров нанокристалла. Как видно из рис. 7, величина внешнего вклада отрицательна и для ОЦК-металлов по модулю в два-три раза выше, чем для ГЦК-металлов. Размерная зависимость $f_{\omega 12}^{(e 0)}(h k l)$ для обеих кристаллических структур выражается полиномиальной функцией шестой степени, но для металлов с ОЦК-структурой она значительнее.

Мы рассчитали МЭ граней для кристаллов палладия, платины, иридия, родия, ниобия, молибдена, тантала и вольфрама на границе с собственными расплавами. Полученные результаты представлены на рис. 8 на примере МЭ грани (110).

Как видно из графиков (рис. 8), МЭ граней на границе с собственным расплавом металла нелинейно увеличивается по мере роста размера кристалла. Размерная зависимость МЭ нанокристаллов (рис. 8) по характеру аналогична размерной зависимости МЭ ориентированных тонких пленок переходных металлов на границе с вакуумом, рассчитанной данным методом [25]. Но величина МЭ граней нано- и макрокристаллов на границе с собственным расплавом значительно ниже (более, чем на 45\%) поверхностной энергии тонких пленок и макрокристаллов на границе с вакуумом [25].

Размерную зависимость МЭ граней можно в общем виде представить как полином шестой степени с достоверностью аппроксимации, равной единице,

$$
f_{\omega 12}(\bar{R})=-a \bar{R}^{6}+b \bar{R}^{5}-c \bar{R}^{4}+d \bar{R}^{3}-g \bar{R}^{2}+h \bar{R}-j,
$$

где $a, b, c, d, g, h, j-$ положительные действительные числа, $\bar{R}$ - усредненный по граням размер нанокристалла.

Приравнивая (18) к нулю и решая получившееся уравнение относительно $\bar{R}$, получаем значение размера $\bar{R}$ наночастицы от 0.2 до $0.5 \mathrm{~nm}$ для рассматриваемых в работе металлов. Следовательно, развитый нами метод расчета размерной зависимости МЭ удовлетворяет физически обоснованному требованию $f_{\omega 12}^{(T)}(h k l)=0$ при исчезновении различия фаз [17]. 

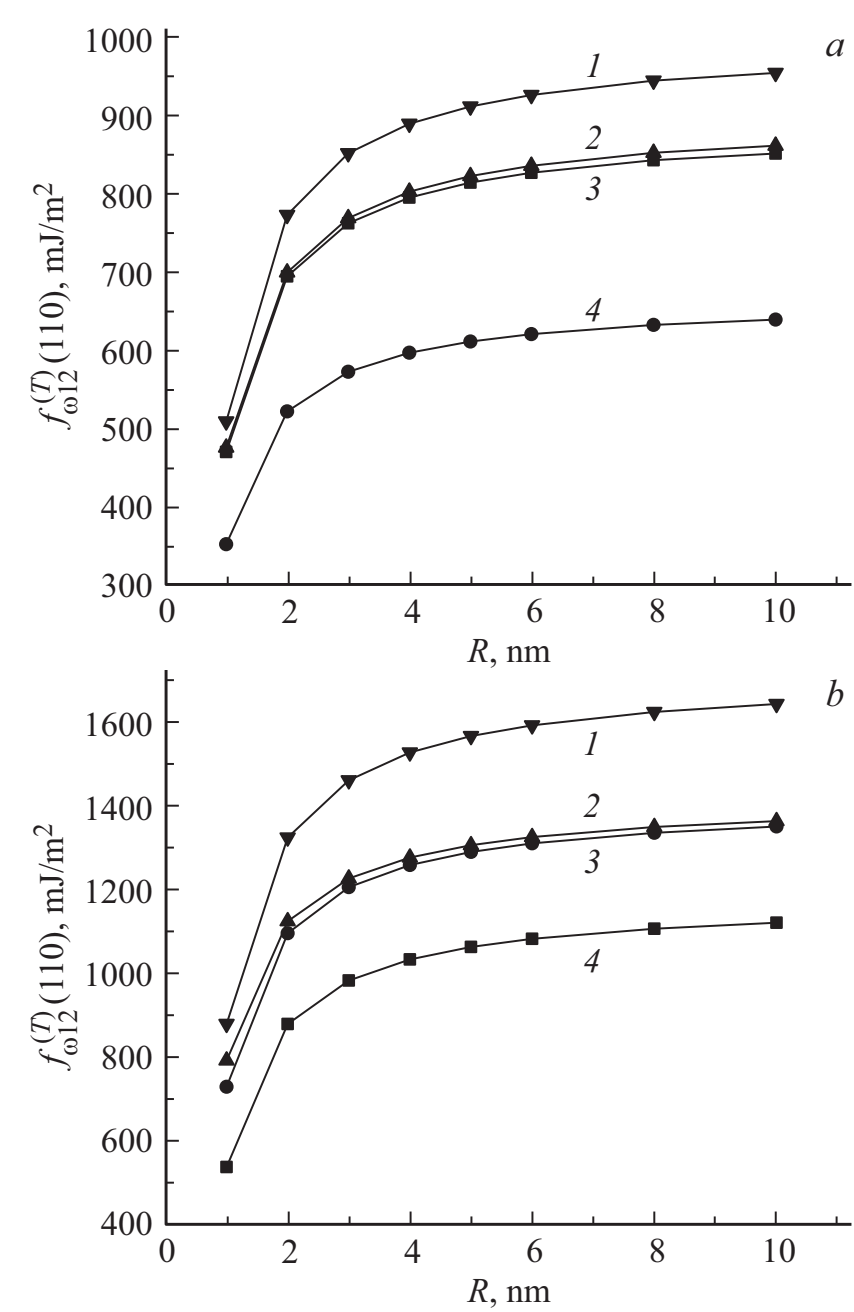

Рис. 8. Межфазная энергия $4 d$ - и $5 d$-металлов на границе с собственным расплавом при $293 \mathrm{~K}:(a) 1-\mathrm{Pt}, 2-\mathrm{Ir}, 3-\mathrm{Rh}$, $4-\mathrm{Pd}$. (b) $1-\mathrm{W}, 2-\mathrm{Mo}, 3-\mathrm{Ta}, 4-\mathrm{Nb}$.

К сожалению, в литературе крайне мало данных по МЭ и МН металлических частиц. Холломон и Тарнбалл [3] методом кристаллизации переохлажденного расплава платины получили значение МЭ $240 \mathrm{~mJ} / \mathrm{m}^{2}$. В работе [32] приведено значение МЭ платины $323 \mathrm{~mJ} / \mathrm{m}^{2}$, полученное по измерению двугранного угла малоуговой границы. Усредненное по граням значение МЭ нанокристаллов размером $1 \mathrm{~nm}$, полученное нами, находятся в удовлетворительном согласии с данными [3,32].

Из сравнения расчетных значений МЭ с экспериментальными данными по ПЭ поликристаллов видно, что при размере нанокристалла $1 \mathrm{~nm}$ МЭ составляет порядка $20-26 \%$ от ПЭ для $4 d$ - и $5 d$-металлов, а при $\bar{R}=10 \mathrm{~nm}$ от 41 до $48 \%$ от ПЭ, что согласуется с теоретическими оценками других авторов.

В работе [32] по формулам разных авторов были рассчитаны МН и МЭ 62 металлов с учетом температурной и размерной зависимости. Наши результаты по МЭ граней систематически завышены, относительно приведенных в [32].

\section{4. Заключение}

Электронно-статистический метод расчета МЭ металлических кристаллов распространен на случай межфазной границы нанокристалл металла-собственный расплав. При увеличении размера кристалла происходит предельный переход от нанокристалла к макрокристаллу, что позволяет использовать выражения для потенциала и электронной плотности для описания свойств нано-, микро- и макроразмерных объектов. Полученные результаты согласуются с термодинамическими представлениями и адекватно описывают изменение величины МЭ граней нанокристаллов переходных металлов на границе с жидкой металлической фазой.

\section{Список литературы}

[1] D. Turnbull, R.E. Cech. J. Appl. Phys. 21, 804 (1950).

[2] D. Turnbull. J. Appl. Phys. 21, 1022 (1950).

[3] Н. Холломон, Л. Тарнбалл. УФН 1, 304 (1956).

[4] M.E. Glicksman, C. Vold. Acta Metal. 17, 1 (1969).

[5] L. Felberbaum, A. Rossoll, A. Mortensen. J. Mater. Sci. 40, 3121 (2005).

[6] M. Erol, K. Keşlioğlu, N. Maraşli. Metallurg. Mater. Transactions A 38, 1539 (2007).

[7] K. Keşlioğlu, N. Maraşh. Mater. Sci. Eng. A 369, 294 (2004).

[8] Y. Kaygısız, S. Akbulut, Y. Ocak, K. Keşlioğlu, N. Maraşlı, E. Çadırlı, H. Kaya. J. Alloys Comp. 487, 103 (2009).

[9] D.R.H. Jones. J. Mater. Sci. 9, 1 (1974).

[10] V.I. Mazhukin, A.V. Shapranov, V.E. Perezhigin, O.N. Koroleva, A.V. Mazhukin. Mathemat. Models Comp. Simulat. 9, 448 (2017).

[11] S.R. Wilson, M.I. Mendelev. J. Chem. Phys. 144, 144707 (2016).

[12] J.J. Hoyt, M. Asta, A. Karma. Phys. Rev. Lett. 86, 5530 (2001).

[13] Д.Н. Соколов, Н.Ю. Сдобняков, П.В. Комаров. В сб.: Физико-химические аспекты изучения кластеров, наноструктур и наноматериалов / Под ред. В.М. Самсонова, Н.Ю. Сдобнякова. Тверской гос. ун-т, Тверь (2011) 3, $284 \mathrm{c}$.

[14] Л.М. Щербаков. В сб.: Поверхностные явления в расплавах и процессах порошковой металлургии / Под. ред. С.Н. Задумкина. Из-во АН УССР, Киев (1963). С. 38.

[15] Т.М. Таова, М.Х. Хоконов. В сб.: Физика межфазных явлений / Под ред. Х.Б. Хоконова. КБГУ, Нальчик (1984). C. 88 .

[16] Т.М. Таова, М.Х. Хоконов. В сб. тр. I Междунар. симпозиума „Плавление и кристаллизация металлов и оксидов“. ИПО ПИ ЮФУ, Ростов н/Д. (2007). С. 164.

[17] М.Н. Магомедов. ФТТ 46, 924 (2004).

[18] М.Н. Магомедов. ЖТФ 84, 46 (2014).

[19] В.М. Яковлев, А.И. Крестелев. Письма в ЖТФ 24, 5, 81 (1998).

[20] A.S. Skapski. Acta Metallurgica 4, 576 (1956).

[21] С.Н. Задумкин. Изв. АН СССР. ОТН. Металлургия и топливо 1, 55 (1961).

[22] С.Н. Задумкин. ФММ 13, 1. 24 (1962). 
[23] С.Н. Задумкин, В.К. Кумыков, И.Г. Шебзухова. В сб.: тр. межвуз. науч. конф. по физике межфазных явлений и избранным вопросам математики, посвященной 50-летию образования СССР / Под ред. С.Н. Задумкина. КБГУ, Нальчик (1972). 3, с. 10.

[24] И.Г. Шебзухова, Л.П. Арефьева, Х.Б. Хоконов. В сб.: Физико-химические аспекты изучения кластеров, наноструктур и наноматериалов / Под ред. В.М. Самсонова, Н.Ю. Сдобнякова. Тверской гос. ун-т, Тверь (2012). 4, c. 319 .

[25] Л.П. Арефьева, Т.Г. Шебзухова. В сб.: Физико-химические аспекты изучения кластеров, наноструктур и наноматериалов / Под ред. В.М. Самсонова, Н.Ю. Сдобнякова. Тверской гос. ун-т, Тверь (2016). 8, с. 26.

[26] Л.П. Арефьева, И.Г. Шебзухова. В сб.: Физико-химические аспекты изучения кластеров, наноструктур и наноматериалов / Под ред. В.М. Самсонова, Н.Ю. Сдобнякова. Тверской гос. ун-т, Тверь (2013). 5, с. 20.

[27] Х.Б. Хоконов, С.Н. Задумкин. В сб.: Поверхностные явления в расплавах и возникающих из них твердых фазах / Под ред. С.Н. Задумкина. Кабардино-Балкарское книжн. изд-во, Нальчик (1965). С. 75.

[28] С.Н. Задумкин. ФММ 11, 3, 331 (1961).

[29] Э.Л. Нагаев. УФН 162, 9, 49 (1992).

[30] П. Гамбош. Статистическая теория атома и ее применение. ИЛ, М. (1951). 337 с.

[31] С.Н. Задумкин, И.Г. Шебзухова, Р.М. Дигилов. В сб.: Физическая химия поверхностных явлений в расплавах / Под ред. С.Н. Задумкина. Наук. думка, Киев (1971). С. 32.

[32] H.M. Lu. Solid State Phenomena 155, 3 (2009).

Редактор Т.Н. Василевская 